ewer found last year has added three characters to those previously known. Even more important, however, to the historian and Biblical student, is a series of letters which belongs to the period immediately before the destruction of the city by Nebuchadnezzar in 598 в.c. The letters, mostly complete, and in some instances running to some length, are on seventeen ostraka which were found among the debris of the guard-room of the gate giving access to the fortress at the south-western corner of the Tell. They are written in ink in an early form of Hebrew, and according to a decipherment and translation made by Prof. Harry Torczyner, of the University of $J$ erusalem, were addressed to the commander of the garrison of Lachish from a subordinate command. One letter is much concerned with the observation of signals and suggests that it refers to a system of smoke signals by which communications were maintained between Lachish and the supreme command. This letter also refers to Lachish by name.

In a list of names of individuals in the correspondence a form compounded with yahu-a form of invocation of Yahweh (Jehovah)-predominates; but one among the names of the fathers of the individuals cited is given, not as a yahu compound, but as an El-compound (El-Natan). This points to a change from El to Yahweh worship within the lives of father and son, probably a result, it is suggested, of the reforms of Josiah. Of even greater interest to Biblical scholars is a reference to a prophet who had been the cause of disturbance, and the passing of a commander-in-chief, Akhboryahu, son of El-Natan, on his way to Egypt, which is clearly a reference to persons and incidents mentioned in Jeremiah xxvi, 20-22.

\title{
Scientific Management
}

$\mathrm{T}$ HE papers given at the Sixth International Congress for Scientific Management held in London during the past week have been available in print for members since early in May (Secretary of the Congress, 21 Tothill Street, London, S.W.1). They are published in six volumes corresponding with the six sections of the Congress and are grouped under subject headings relating to the particular themes to be considered at the four sessions held by each section. Nearly all the 200 papers have a certain scientific interest, so that any selection from them is difficult.

Dealing with the subject of preliminary education for management, Mr. A. P. M. Fleming points out that at present provision is seldom made in industrial concerns to ensure continuity of good management beyond a single generation. The methods of selection of staff are discussed by competent authorities from the German, French, British, Dutch, Italian and Swiss points of view, so that a comprehensive picture of modern thought on this subject is available. When summarised, the information should be of great importance to educational advisers who have to help to place young men in life.

Opinion is hardening in business circles that the entrants from school should receive a good deal more vocational training than at present. The recruitment of personnel suitable for high administrative positions is likewise discussed in several papers. The National Institute of Industrial Psychology is responsible for a communication which deals with the vexed question of promotion versus engagement from outside on the basis of the experience gained by the Institute, and schemes are put forward showing how to discover men within a company for training and how to select from outside. The Dutch authors regard personnel selection as a profession in itself : the Italians would invoke a psychotechnical criterion.

It is widely said that there is a shortage of men to-day for the senior posts, probably because of the toll taken by the War of the more enterprising. It is clear that there is world-wide concern with regard to leadership : hence the numerous suggestions as to the form of training. The volume containing the educational and training section papers deserves to be read as a whole both by executives who have the choice of their successors and by the educationists.
In the development section the bulk of the paper's discuss the correct methods of inculcating modern management principles and practices. They come from many lands and cover a variety of problems. Thus C. G. Renold describes the steps taken in the merging and subsequent rationalisation of a group of companies employing 5,000 people; he attempts to assess the costs involved and the benefits resulting : this is a most valuable contribution. H. J. Mitchell discusses the methods adopted by Imperial Chemical Industries, Ltd., of which he is a leading director, in the management of its many activities, the general desire being to have a stable organisation where stability is essential but a high degree of flexibility in other directions where research and development require it. Whereas management of the groups is decentralised, finance is fully centralised. The Company's whole-time directors are relieved of direct executive duties, and a considerable amount of authority and responsibility is delegated. This account of the management of our largest undertaking contrasts with one, describing the methods used in a small tapestry factory, which follows it.

The account of the I.C.I. scheme of management will be widely studied, the more so as it is realised both that the problem of the successful management of so large an organisation is one of very great difficulty and that the difficulties have been largely overcome by I.C.I. along the lines outlined.

A second series of papers in this volume deals with the rôle of institutions, trade and other associations in relation to management problems. A thoughtful summary contributed by a committee representing the Federation of British Industries analyses the association movement as affecting efficiency, and makes some constructive suggestions as to the manner in which trade associations can be of assistance.

In the manufacturing section the subject of budgetary control attracts first notice. An important review representing the accumulated experience of some of the leading firms in Great Britain is contributed by Roland Dunkerley. The idea indicated by the term is to substitute considered intention for opportunism in business; it has been much discussed and studied during recent years, and the theories of 
such control are firmly established and widely known. Its application is proving increasingly successful though it is necessary to adjust the principles to meet the varying demands of the various industries.

A second group of papers deals with scientific methods applied to works management in a number of specific examples.

Distribution is becoming very definitely a science. It is axiomatic that the manufacturer of a new product must sell it and that the true market is always the ultimate user. A paper contributed by the Advertising Association of Great Britain gives a particularly good summary of the routes through which a new product can be distributed to the public, with concrete examples of recent introductions. Any reader of this volume who has the task of introducing a new product can easily ascertain the international views as to how he should begin his task. Large organisations are finding it worth while to establish special departments for marketing research : some of the methods employed and results obtained in the United States are described by Mr. O. F. Roost. As one industry after another reaches a point where it is able to produce more than the market can apparently consume, competition becomes keener and the need for more intimate and accurate knowledge of existing markets and possible new ones becomes apparent.
E.F.A.

\section{The Metallic State}

A CONFERENCE on "The Metallic State" was held in the University of Bristol at the H. H. Wills Physics Laboratory on July 2-5, about forty visitors being present from other parts of England and from the Continent. Most of the visitors were housed in Wills Hall, one of the University halls of residence.

At the opening session of the Conference, Dr. J. A. Prins (Groningen) gave an account of the results obtained at the University of Groningen on the absorption and emission of X-rays by metals. The absorption spectrum in crystalline solids has a fine structure extending several hundred electron volts on the short wave-length side of the edge, and depending in its general features only on the structure, and not on the atomic constitution of the crystal. A theoretical explanation due to Kronig was discussed, which relates the phenomenon to the Bragg reflection of the ejected electrons. Dr. H. W. B. Skinner (Bristol) showed how the study of emission bands in the ultrasoft region can give information about the occupied electronic states in metals. Prof. W. L. Bragg (Manchester) gave a report of some recent results obtained by Sykes on the formation of a superstructure in copper. gold alloys, and Mr. J. D. Bernal (Cambridge) discussed the factors which determine the crystal structure of alloys, pointing out especially that the atomic radii of the constituents have often a decisive influence.

The morning of July 3 was devoted to a discussion of the liquid and amorphous states. Prof. H. Mark (Vienna) gave an account of recent theories of electrical conductivity, and Dr. J. A. Prins gave a report on his own work on amorphous antimony. Dr. G. W. Brindley (Leeds) showed the effect of filing on the intensity of X-ray reflection from metals. In the afternoon there was a discussion on the properties of metallic bismuth, in which Prof. A. Goetz (Pasadena), Dr. N. Thompson (Bristol), Dr. D. Shoenberg (Cambridge) and Dr. H. Jones (Bristol) took part. Bismuth is peculiar in that very small quantities (less than 0.1 per cent) of lead, tin or other metals in solid solution have a very marked effect on its electrical conductivity and diamagnetic susceptibility. Prof. Goetz expressed the opinion that these facts suggest the existence in bismuth of a microcrystalline superstructure of the kind postulated by $Z_{w i c k y}$, but an alternative explanation was suggested in terms of the wave mechanical theories due to Pejerls and Jones. These theories, however, will require further development before any quantitative account of the facts can be given.

On July 4, Prof. W. Gerlach (Munich) gave an account of the work carried out in his laboratory on the electrical resistance of nickel and of some of its alloys. The resistance of nickel decreases in a magnetic field, the decrease being proportional to the change in $\sigma^{2}$, where $\sigma$ is the magnetisation. Further, the resistance plotted against temperature shows a kink at the Curie point. A possible explanation of the effect was suggested by Prof. N. F. Mott (Bristol). Dr. E. C. Stoner (Leeds) pointed out that various methods of determining the Weiss intramolecular field constant in nickel give very discordant results, and suggested an explanation.

On July 5, a discussion on supra-conductivity was opened by Dr. J. M. Casimir (Leyden), who gave an account of the fundamental experiments of Meissner, and of de Haas and Mrs. Casimir, and of the important theoretical advances of Gorter, Casimir and London. Mr. K. Mendelssohn (Oxford) gave an account of the behaviour of certain alloys. It appears that though great progress has been made towards the understanding of the thermodynamics and electrodynamics of a supra-conductor, we are still as far as ever from knowing the cause of the phenomenon. Dr. $H$. Niewodniczański and Mr. C. J. Milner (Mond Laboratory, Cambridge) discussed the electrical conductivity of non-supra-conductors, and here also the results of theory are by no means in accord with experiment, and the opinion was expressed on several sides that all theories are wrong below $4^{\circ} \mathrm{K}$. Prof. F. Simon (Oxford) and Dr. E. Teller (London) also discussed the possibility of using nuclear spins to obtain yet lower temperatures than can be obtained with ordinary paramagnetics by the magnetic cooling method.

An interesting feature of the Conference was the frequent mention of experimental facts for which no quantitative theoretical explanation could be given. Considerable advances have recently been made in the quantum theory of the metallic state, and it is now possible for the theorist to give an indication of why certain metals have their particular crystal structures, magnetic properties and electrical conductivities. Nevertheless, the theory is as yet far from being able to give such a complete account of the experimental data as is possible, for example, in the field of atomic spectra. 